\title{
Studies on storability of maize-millet based soy fortified extruded snacks
}

Chandrahas Sahu, S. Patel and D. Khokhar

Received : $10.04 .2018 ;$ Accepted : 13.04 .2018

See end of the Paper for authors' affiliation

Correspondence to :

Chandrahas Sahu Department of Dairy Engineering, College of Dairy Science and Food Technology, Chhatisgarh Kamdhenu Vishwavidyalaya, Raipur (C.G.) India

Email : ercsahu2003@gmail.

com
Abstract : Storability and shelf-life of any products are most important for producers as well as consumers. Shelf-life of products depends on moisture content of the products which should be stored in different packaging materials and storage conditions. In the present study storage stability of extruded snack were carried out at accelerated conditions of $40^{\circ} \mathrm{C}$ and $90 \% \mathrm{RH}$. The extruded snacks using ingredients: maize, finger millet, defatted soy and elephant foot yam in the proportion of 40:30:20:10, respectively was developed under optimized conditions of $110^{\circ} \mathrm{C}$ barrel temperature, $301 \mathrm{rpm}$ screw speed and 14\% moisture content. The effect of storage period on the quality of extruded snacks packed in pouches of low density polyethylene (LDPE), aluminium foil, high density polyethylene (HDPE) and metalized polyethylene terephthalate (MPET) at accelerated condition were determined. The quality parameters such as moisture content, hardness and crispness for storage stability of extruded snacks were evaluated. Packaging material affects the quality of extruded snack products during storage. Packaging material and storage period both had significantly $(\mathrm{P}<0.05)$ affected the moisture content, hardness and crispness of extruded snack product. On the basis of packaging material used, the extruded snacks packed in LDPE pouches showed greater changes to quality parameters and minimum packed in MPET. The shelf-life of extruded snack packed in LDPE, aluminium foil, HDPE and MPET under accelerated condition of storage was found to be 6, 8, 11 and 35 days, respectively. Hence MPET was better packaging material for storing the extruded snack.

- Key words : Crispness, Extruded snack, Hardness, Moisture content, Packaging, Shelf-life

- How to cite this paper : Sahu, Chandrahas, Patel, S. and Khokhar, D. (2018). Studies on storability of maize-millet based soy fortified extruded snacks. Internat. J. Agric. Engg., 11(Sp. Issue) : 46-52, DOI: 10.15740/HAS/IJAE/11.Sp. Issue/46-52. 